Report

\title{
Development of a knowledge scale about breast cancer and heredity (BCHK)
}

\author{
Nancy Ondrusek ${ }^{1}$, Ellen Warner ${ }^{2}$, and Vivek Goel ${ }^{3}$ \\ ${ }^{1}$ University of Toronto Joint Center for Bioethics; ${ }^{2}$ Toronto Sunnybrook Regional Cancer Center; University of \\ Toronto; ${ }^{3}$ Department of Public Health Sciences, University of Toronto; Institute for Clinical Evaluative Sciences \\ in Ontario
}

Key words: family history, hereditary breast cancer, knowledge

\begin{abstract}
Summary
An 11-item questionnaire, the Breast Cancer and Heredity Knowledge Scale (BCHK), was developed to test general knowledge about breast cancer and hereditary breast cancer (HBC) among women at low to moderate risk of HBC. The BCHK measures knowledge about breast cancer incidence and prognosis, risk factors, screening, disease presentation and treatment, and HBC. Scale items were generated from focus group interviews, previously published breast cancer knowledge scales, and consulation with a multidisciplinary research team, including health professionals and women with breast cancer or a family history of breast cancer. A 27 -item draft scale was tested on 36 breast clinic patients and 17 women from the general public. Results were used to develop the final 11-item scale. Development of the scale and its potential uses are discussed.
\end{abstract}

\section{Introduction}

Breast cancer is the most common cancer among North American women, who currently face approximately a 1 in 9 lifetime risk of the disease [1]. The recent cloning of two breast cancer susceptibility genes, BRCA1 and BRCA2, has now created the possibility of predictive genetic testing. The resulting media coverage has led many women with a family history of breast cancer to wonder whether they should be tested. Although as many as $20 \%$ of women have a family history of breast cancer [2], BRCA1 and BRCA2 mutations appear to account for no more than $5 \%$ of all cases of the disease [3]. Thus, the majority of women with a family history of breast cancer do not possess BRCA1 or BRCA2 mutations, and do not face the estimated $85 \%$ lifetime risk of breast cancer [4] associated with these mutations.

Many women are seeking information about HBC from a variety of sources, including family physicians, television and print media, and the Internet. While women with very strong family histories of breast cancer are being referred to specialized familial breast cancer clinics and are receiving extensive counselling, it is not known whether women with less striking family histories, the majority of whom are not seen at these specialized clinics, are getting the information they need and coming away with an accurate understanding of their risk.

For this latter group of women, who are at low to moderate risk for $\mathrm{HBC}$, genetic testing is currently not indicated, and, given the technical limitations, clinical uncertainties, and psychosocial risks of testing, it is not likely to become an option in the near future. Therefore, unlike women at high risk for HBC, who are eligible for genetic testing and need very specific details about the nature of testing and the interpretation and implications of test results, women at low to moderate risk need more general information about the role of hereditary risk relative to other risk factors, and the need for regular breast cancer screening for all women. The optimal means of educating this large and heterogeneous group of women is unknown and several models are currently under development by ourselves as well as others. As the majority of women with a family history of breast cancer fall into this lower risk group, any educational approaches will potentially affect large numbers of women, and therefore must be evaluated carefully. While a knowledge scale has been previously developed by the US National Institutes of Health Cancer Genetic Studies Consortium for women at high risk of $\mathrm{HBC}[5,6]$ this scale is not suitable for the lower risk group. To address the need for an evaluative 
tool specific to the information needs of women at low to moderate risk of $\mathrm{HBC}$, we have developed a brief, self-administered knowledge scale about breast cancer and heredity specifically for this group.

\section{Method}

\section{Focus groups}

In order to determine the information needs of women who are at low to moderate risk of $\mathrm{HBC}$, we conducted a series of 4 focus groups: 1 group each of breast cancer survivors and relatives of breast cancer patients, and 2 groups of women from the general population, ages $23-46$ and ages $45-65$. The results of these focus group interviews indicated that many women had misconceptions about breast cancer or lacked knowledge in specific areas including risk factors, options (or lack of them) for primary and secondary prevention, symptoms, natural history, and treatment. Knowledge about genetics and HBC was generally poor.

\section{Generation of draft scale for pilot testing}

Based on the focus group results we felt that it was important to measure general knowledge about breast cancer, as well as specific knowledge about genetics and $\mathrm{HBC}$. The BCHK was, therefore, designed to examine knowledge of four breast cancer subject areas: (i) incidence and risk factors; (ii) disease presentation and treatment; (iii) screening; and (iv) genetics.

Specific items were generated based on the anticipated information needs of women at low to moderate risk of breast cancer as determined by a review of the literature, including previously validated breast cancer knowledge scales, the focus group results, and consultation with individuals from medical oncology, surgical oncology, medical genetics, epidemiology, psychology, sociology, and bioethics, as well as breast cancer patients and their family members directly involved with this project.

Forty-six items were generated. Of these, 29 were selected by the multidisciplinary research team and pre-tested for readability, comprehensibility, and acceptibility on a convenience sample of 15 healthy women from a variety of non-medical professions. The resulting 27 item scale contained 6 items each on disease presentation and treatment, and screening, 7 items on incidence and risk factors, and 8 items on genetics. The scale was formatted as a series of statements to which respondents were asked to 'strongly agree', 'agree', 'disagree', or 'strongly disagree', with a middle category for 'unsure'.

\section{Pilot test of draft scale}

The 27 item draft scale (Table 1) was tested on a sample of 53 women, recruited from several breast clinics at the Toronto Sunnybrook Regional Cancer Centre (TSRCC) and from the University community, representing a range of ages and a range of knowledge levels about breast cancer. Women who were not fluent in English were excluded from participation, as were members of the University community who identified themselves as having 'special knowledge about breast cancer or genetics'. In addition, patients in the clinics were not approached for participation if they were identified by the clinic staff as particularly anxious at the time of their appointment or had recently received distressing news about their condition. Written consent was obtained for all study subjects; this research project was approved by the University of Toronto Human Subjects Review Committee, and by the Research Ethics Board at Sunnybrook Health Science Centre.

Participants completed the knowledge scale at the time of enrolment, and were then asked to comment on comprehensibility and acceptability of items. Participants subsequently completed the same scale 2-4 weeks later. A correct response to a statement, whether 'strongly agree' or 'strongly disagree', was assigned a value of 2. A less certain response of 'agree' or 'disagree' was assigned a value of 1 . Incorrect responses were given a negative value, and 'unsure' response were assigned a value of 0 .

\section{Generation of final scale}

Selection of items for the final scale was based on examination of qualitative comments about the items, endorsement, test-retest reliability, item-to-item correlations (factor analysis), and the need to maintain content validity. All statistical analyses were performed using the STATA ${ }^{\mathbb{R}}$ statistical/data analysis computer software.

\section{Results}

\section{Subjects}

Thirty-six of the subjects were women attending one of the breast clinics at the Toronto Sunnybrook Regional Cancer Centre for suspected breast disease $(n=8)$, counselling about HBC $(\mathrm{n}=19)$, or follow-up of breast cancer $(n=5)$ or benign breast disease $(n=4)$. The remaining 17 subjects had no special interest in or knowledge about breast cancer, and included 8 hospital 
Table 1. BCHK draft and final items, showing the primary rationale for deleting items from final scale

\begin{tabular}{|c|c|c|}
\hline & $\begin{array}{l}\text { Mean score } \\
\text { (range }=-2 \text { to } 2 \text { ) }\end{array}$ & $\begin{array}{l}\text { Rationale for deleting } \\
\text { items* }\end{array}$ \\
\hline \multicolumn{3}{|l|}{ Incidence and risk factors } \\
\hline $\begin{array}{l}\text { Bruising, bumping, or injuring the breast can cause } \\
\text { breast cancer }\end{array}$ & 0.96 & -endorsement high \\
\hline $\begin{array}{l}\text { Stress is a proven major cause of breast cancer } \\
\text { (Stress has been proven to cause breast cancer) }\end{array}$ & 0.43 & $\begin{array}{l}*(\text { item re-worded) } \\
\text { to improve } \\
\text { comprehensibility) }\end{array}$ \\
\hline $\begin{array}{l}\text { Women with large breasts are more likely to get breast } \\
\text { cancer than women with small breasts }\end{array}$ & 1.02 & -endorsement high \\
\hline $\begin{array}{l}\text { Many women who do not have any of the known risk } \\
\text { factors still get breast cancer }\end{array}$ & 0.98 & $\begin{array}{l}\text {-endorsement high } \\
\text {-content similar to } \\
\text { other items }\end{array}$ \\
\hline $\begin{array}{l}\text { Some women can feel confident that they will never } \\
\text { get breast cancer }\end{array}$ & 0.91 & $\begin{array}{l}\text {-endorsement high } \\
\text {-comprehensibility }\end{array}$ \\
\hline $\begin{array}{l}\text { Over a lifetime, } 1 \text { out of } 9 \text { women will develop breast } \\
\text { cancer }\end{array}$ & 0.71 & * \\
\hline $\begin{array}{l}\text { Women who are over } 50 \text { years of age are more likely } \\
\text { to get breast cancer than are younger women }\end{array}$ & 0.58 & * \\
\hline \multicolumn{3}{|l|}{ Disease presentation and treatment } \\
\hline $\begin{array}{l}\text { Discharge from the nipple may be a sign of breast } \\
\text { cancer }^{\ddagger} \text { (modified) }\end{array}$ & 0.83 & $\begin{array}{l}\text {-endorsement high } \\
\text {-iic }{ }^{\dagger} \text { high }\end{array}$ \\
\hline $\begin{array}{l}\text { Out of every } 100 \text { women diagnosed with breast cancer, } \\
75 \text { are disease free after } 10 \text { years }\end{array}$ & -0.30 & $*$ \\
\hline Breast cancer can spread through the blood stream & 0.06 & -comprehensibility \\
\hline $\begin{array}{l}\text { If a tumour is cancerous, removal of the entire breast is } \\
\text { always necessary }\end{array}$ & 1.26 & -endorsement high \\
\hline $\begin{array}{l}\text { Swelling or enlargement of one breast may be a sign of } \\
\text { breast cancer }{ }^{+} \text {(modified) }\end{array}$ & 0.30 & * \\
\hline $\begin{array}{l}\text { Chemotherapy is always used in the treatment of } \\
\text { breast cancer }\end{array}$ & 0.67 & * \\
\hline \multicolumn{3}{|l|}{ Primary and secondary prevention } \\
\hline $\begin{array}{l}\text { The best time to perform breast self-examination is } \\
\text { just before a woman's menstrual period, when lumps } \\
\text { are most easily detected }{ }^{\dagger \neq} \text { (modified) }\end{array}$ & 0.91 & -comprehensibility \\
\hline $\begin{array}{l}\text { If a woman gets a regular mammogram, she does not } \\
\text { have to do breast self-examination or have physical } \\
\text { examinations }{ }^{+1}\end{array}$ & 1.68 & -endorsement high \\
\hline $\begin{array}{l}\text { Early detection means a greater chance of surviving } \\
\text { breast cancer }\end{array}$ & 1.77 & -endorsement high \\
\hline $\begin{array}{l}\text { A complete breast examination includes examination } \\
\text { of the underarm and neck regions }\end{array}$ & 1.08 & $\begin{array}{l}\text {-endorsement high } \\
\text {-comprehensibility }\end{array}$ \\
\hline $\begin{array}{l}\text { Women over age } 50 \text { should have mammograms at } \\
\text { least every } 2 \text { years }\end{array}$ & 0.83 & * \\
\hline Mammography can detect lumps that can’t be felt ${ }^{\dagger \dagger}$ & 1.32 & -endorsement high \\
\hline
\end{tabular}




\begin{tabular}{lll}
\hline & $\begin{array}{l}\text { Mean score } \\
\text { (range }=-2 \text { to 2) }\end{array}$ & $\begin{array}{l}\text { Rationale for deleting } \\
\text { items* }\end{array}$ \\
\hline $\begin{array}{l}\text { Genetics } \\
\text { A woman whose mother was diagnosed with breast } \\
\text { cancer at age } 69 \text { is considered to be at high risk for } \\
\text { breast cancer }\end{array}$ & 0.17 & $*$ \\
$\begin{array}{l}\text { A woman can inherit breast cancer gene mutations } \\
\text { from her mother or her father }\end{array}$ & 0.64 & $\begin{array}{l}\text {-comprehensibility } \\
\text {-iic high }\end{array}$ \\
$\begin{array}{l}\text { Most women who develop breast cancer do not have a } \\
\text { family history of the disease. }\end{array}$ & 0.08 & $\begin{array}{l}\text {-comprehensibility } \\
\text {-ic high } \\
\text { One in ten women have inherited breast cancer gene } \\
\text { mutations }\end{array}$ \\
$\begin{array}{l}\text { Ovarian cancer and breast cancer in the same family } \\
\text { can be a sign of hereditary breast cancer } \\
\text { Testing for breast cancer gene mutations can tell a } \\
\text { woman if she has breast cancer }\end{array}$ & -0.21 & $\begin{array}{l}\text { responses } \\
\text { Men cannot inherit breast cancer gene mutations } \\
\text { Some women are born with a gene mutation that } \\
\text { greatly increases their risk of getting breast cancer }\end{array}$ \\
\hline
\end{tabular}

* Retained items; ${ }^{\dagger}$ inter-item correlation; ${ }^{\ddagger}$ from, or modified from [7]; ${ }^{*}$ from, or modified from [15]

administrators (non-medical departments), 8 graduate students (departments of philosophy or bioethics), and 1 retired secretary (non-medical).

\section{Comprehensibility and acceptability}

Thirty-three of the 53 respondents ( $72 \%$ of patients and $41 \%$ of non-patients) provided specific comments on the wording of the items. Almost half of the comments indicated general approval, such as: 'good questions' or 'easy to understand'. Twenty-three respondents had comments about wording and clarity of specific items. Two respondents noted that the questions would not be appropriate for individuals who were not fluent in English. In addition, 3 respondents criticized the use of the 'strongly agree' and 'strongly disagree' categories. None of the 53 respondents indicated that the scale was generally unclear or in any way distressing.

\section{Frequency of endorsement}

Endorsement of the items in the draft scale was highly variable, ranging from 6.0 to $100 \%$ correct, and from 0.0 to $69 \%$ unsure. Frequency of correct responses in the 'strongly' agree or disagree category ranged from 0.0 to $77.4 \%$, while frequency of incorrect response in the 'strongly' agree or disagree category ranged from 0.0 to $9.4 \%$.
Mean scores across all subjects for specific items ranged from -0.30 (for an item about survival rates) to 1.77 (for an item about the benefits of early detection) out of a possible 2. Mean total score across all items was 0.72 . Total scores for each subject ranged from 0.22 to 1.48 out of a possible 2.0.

\section{Reliability}

Of the original 53 participants, 38 also completed the retest $(72 \%)$. Test-retest reliability for the draft scale was 0.76 . Mean total scores for participants completing both tests was 0.73 and 0.76 at test and retest, respectively.

\section{Item to item correlation}

Factor analysis was performed to determine the extent to which individual items were measuring unique aspects of the respondents' knowledge, and therefore the relative contribution of each item to the total scale. A number of items strongly correlated with several other items, and were dropped from the final scale. For example, the scores for an item about nipple discharge as a symptom of breast cancer correlated with the scores for several other items across different subject areas, and the scores for two of the genetics items correlated with the scores for other genetics items. 


\section{Final scale}

The decision to retain or delete each item was based on a balancing of the various statistical and qualitative considerations (Table 1). The final scale contains 11 items. The items fall into 3 main subject areas: incidence and etiology ( 3 items), screening, disease presentation, and treatment (4 items), and genetics (4 items). The final scale contains two items slightly modified from the breast cancer knowledge scale developed by Vaeth [7].

The mean knowledge level as assessed by the scores of the final 11 items was 0.40 (out of a possible 2.0) at enrolment, and 0.43 at retest. The correlation in scores between enrolment and retest was 0.81 . The Flesch reading level [8] of the final $\mathrm{BCHK}$ is grade 8.2. The scale can be completed in less than $5 \mathrm{~min}$.

\section{Discussion}

We have developed a knowledge scale (the BCHK) specifically for evaluation of knowledge among women at low to moderate risk of HBC. We feel that the information needs of women at low to moderate risk for hereditary breast cancer differ from the information needs of women who are at high risk. A number of scales have previously been developed to measure women's knowledge about breast cancer screening [9], surgical options [10], breast cancer risks, detection, and treatment [7, 11], and genetic testing for HBC (NIH Cancer Genetics Consortium in [5, 6]). None of the existing scales, however, includes items about both genetics and the other breast cancer subject areas. Furthermore, these scales each contain items that reflect the relatively detailed level of knowledge expected within specific populations, such as knowledge about side effects of treatment that would be particularly relevant to breast cancer patients, rather than the more general knowledge relevant to a well population.

The BCHK was developed to measure general knowledge about breast cancer, including incidence and prognosis, risk factors, screening, disease presentation, and treatment, as well as knowledge of HBC. Inclusion of content on general knowledge was considered important because the appreciation of genetic information about breast cancer requires some context, and our focus group results indicated that for many women this background knowledge is lacking.

During pilot testing of the draft scale, several study participants suggested alternatives to the choice of categories for response. One objection was to the use of a 5 point rather than a 3 point scale, and the other two comments suggested that the use of the words 'agree' and 'disagree' are inappropriate as those terms indicate opinion rather than fact. We had considered these same concerns early in the development of this scale. The 5 point scale was chosen to allow detection of different levels of certainty. The terms 'agree' and 'disagree' were chosen because other wording alternatives (2 questions: (i) true/false, (ii) how strong is your answer) were judged by the research team to be too cumbersome. Furthermore, we had received positive feedback from many of the participants at all stages in the development of this scale, and these terms were used successfully by one of us (VG) in a previous study [12].

It is of interest to note that respondents correctly choose the 'strongly agree' or 'strongly disagree' on average $23.4 \%$ of the time, but only incorrectly choose the 'strongly' categories $2.1 \%$ of the time, suggesting self-awareness of gaps in knowledge, rather than the possession of strong misconceptions.

A number of qualitative and quantitative measures are used to guide scale development. Selection of the final 11 items of the BCHK was based on balancing the various statistical and qualitative measures. Several items were discarded bacause they were answered correctly by all or almost all of the respondents. One item about the prevalence of BRCA1 and 2 mutations was discarded because a majority of subjects (69\%) had responded 'unsure'. A number of items were discarded because of concerns about clarity of the wording.

Content validity of a scale refers to the extent to which the scale covers the relevant subject areas [13]. The initial choice of subject areas, and of the specific items, was determined by consultation with a number of groups as described in the methods section. Maintenance of content validity for the 11 item final scale was part of the item selection process. The final items reflect the kind of information we feel is important to women at low to moderate risk of HBC: breast cancer incidence, prognosis and risk factors, screening, disease presentation and treatment, and genetics.

Although the draft scale contained 6 items relating to screening, only one of these items was retained in the final scale. Screening was emphasized in the draft scale because, given the lack of options for preventing breast cancer, early detection is an important focus for women at all levels of risk. Furthermore, many of the women in the focus groups lacked knowledge about this subject area. Four of the items were dropped, however, because of the high percentage of correct responses (ranging from 81-100\%), suggesting a high degree of awareness about screening among the women in this study. 
One explanation for the apparent difference between the focus groups and the participants in the pilot study in knowledge about screening, is that the items generated for the draft knowledge scale were very general and thus reflected the least challenging or most commonly known facts. As shown in Table 1, the items that were dropped because of high scores referred very generally to the roles of early detection and mammography, whereas a more specific item about recommendations for mammography received a broader range of responses. This explanation is supported by Dolan et al. [14], who found that while over $80 \%$ of women in their study were aware of the benefits of mammography for early detection of breast cancer, $55 \%$ incorrectly believed that screening mammography in healthy women should begin at 30-35 years of age.

Criterion validity is established by comparing scores to a previously validated scale (a 'gold standard'). Construct validity is determined by looking for correlations between scores and various factors that usually correlate with knowledge, such as education [13]. Criterion validity was not determined at this phase of the development of the BCHK because no comparable gold standard exists. Construct validity was not examined because the test population was too heterogenous to look for trends in the scores. Construct validity of the BCHK will be examined in a study currently underway with women scheduled for counselling at familial breast clinics. The scale's ability to detect changes in knowledge in response to educational interventions (sensitivity to change) will also be evaluated in this study.

Reliability of a scale can be examined in terms of test-test reliability and internal consistency. Testretest reliability examines the stability of the test over time. Test-retest reliability of the BCHK was high, at 0.81 , with a very slight increase in average score between time 1 and time 2 . The increase may reflect improved test performance with practice, or aquisition of information during the time between the two tests, possibly prompted by the test itself. Internal consistency examines the correlation between the score for each item and the total score. The internal consistency of the final scale, as measured by Cronbach's alpha, was low at 0.23 . Although this low score might be considered problematic for scales measuring a single trait or content domain, a high alpha statistic cannot be expected for a multidimensional knowledge scale such as the BCHK. For example, women may know many facts about mammography, but may know virtually nothing about $\mathrm{HBC}$ or other risk factors. Knowledge of breast cancer treatment, risk factors, symptoms, and misconceptions about breast cancer have been previ- ously shown by factor analysis to sort into separate domains that had only low to moderate correlations with one another [7]. It is likely that women in the general population who are obtaining their information from a variety of sources may learn about one or several aspects of breast cancer without improving their knowledge about other areas. Indeed, results from our focus group interviews indicated that such 'spotty' knowledge may be typical.

In conclusion, the BCHK is an 11 item selfadministered questionnaire designed to test general breast cancer and HBC knowledge of women who have a family history of cancer that is not highly suggestive of a hereditary cancer syndrome. Potential uses of this scale include identification of women who require education in these areas, and the evaluation of the effectiveness of counselling or educational materials designed for this group of women. It should be noted that this paper reports only the development of the BCHK. Until further evaluation has been completed, use of the scale should limited to well defined research studies. We welcome the use of the BCHK by other investigators.

\section{Acknowledgements}

This work was supported by a grant from the Canadian Breast Cancer Research Initiative. Dr. Goel is supported in part by a National Health Scholar Award. The authors wish to thank Dr. Pam Chart, Dr. June Carrol, Dr. Lavina Lickley, Dr. Wendy Meschino, Ms. Jane Boyle, Dr. Brian Doan, Dr. Kathryn Taylor, Ms. Margaret Rao, Ms. Anne Parker, and Ms. Bonnie Basset-Spiers for their suggestions in the development of items for the knowledge scale. We also thank Ms. Elaine Thiel for her contributions to this manuscript.

\section{References}

1. Bryant $\mathrm{H}$, Brasher P: Risks and probabilities of breast cancer: short-term versus lifetime probabilities. Can Med Assoc J 150 (2): 211-216, 1994

2. Slatterly M, Kerver R: A comprehensive evaluation of family history and breast cancer risk. The Utah population data base. JAMA 270 (13): 1563-1568, 1993

3. Hoskins K, Stopfer J, Calzone K, Merajver S, Rebbeck T, Garber J, Weber B: Assessment and counseling for women with a family history of breast cancer. A guide for clinicians. JAMA 273 (7): 577-585, 1995

4. Struewing J, Harge P, Wacholder S, Baker S, Berlin M, McAdams M, Timmerman M, Brody L, Tucker M: The risk of cancer associated with specific mutations of BRCA1 and 
BRCA2 among Ashkenazi Jews. N Engl J Med 336 (20): 1401-1408, 1997

5. Lerman C, Biesecker B, Benkendorf J, Kerner J, GomezCaminero A, Hughes C, Reed M: Controlled trial of pretest education approaches to enhance informed decisionmaking for BRCA1 gene testing. J Natl Cancer Inst 89 (2): 148-157, 1997

6. Lerman C, Narod S, Schulman K, Hughes C, GomezCaminero A, Bonney G, Gold K, Trock B, Main D, Lynch J, Fulmore C, Snyder C, Lemon SJ, Conway T, Tonin P, Lenoir G, Lynch H: BRCA1 testing in families with hereditary breast-ovarian cancer. A prospective study of patient decision making and outcomes. JAMA 275 (24): 1885-1892, 1996

7. Vaeth P: Women's knowledge about breast cancer. Dimensions of knowledge and scale development. Am J Clin Oncol 16 (5): 446-454, 1993

8. Flesch R: A new readability yardstick. J Appl Psych 32: 221-233, 1948

9. Fox S, Klos D, Tsou C, Baum J: Breast cancer screening recommendations: current status of women's knowledge. Fam Community Health 10 (3): 39-50, 1987
10. Ward S, Griffin J: Developing a test of knowledge of surgical options for breast cancer. Cancer Nurs 13 (3): 191-196, 1990

11. Stager J: The comprehensive breast cancer knowledge test: validity and reliability. J Adv Nurs 18: 1 133-1 140, 1993

12. Goel V, Glazier R, Holzapfel S, Puch P, Summers A: Evaluating patient's knowledge of maternal serum screeing. Prenat Diagn 16 (5): 425-430, 1996

13. Streiner D, Norman G: Health measurement scales. A practical guide to their development and use. Oxford University Press, Oxford, 1989

14. Dolan N, Lee A, McDermmot M: Age-related differences in breast carcinoma knowledge, beliefs and perceived risk among women visiting an academic general medicine practice. Cancer 80 (3): 413-420, 1997

15. McCance K, Mooney K, Smith K, Field R: Validity and reliability of a breast cancer knowledge test. Am J Prev Med 6 (2): 93-97, 1990

Address for offprints and correspondence: Dr. Vivek Goel, MSc, FRCP(C), Institute for Clinical Evaluative Sciences - G-Wing, 2075 Bayview Ave., Toronto, Ontario, Canada M4N 3M5; Tel: 416480 4055; Fax: 4164806048 